\title{
PENGEMBANGAN MULTIMEDIA E-LEARNING BERBASIS APLIKASI KEKINIAN PADA PEMBELAJARAN GEOMETRI UNTUK SISWA KELAS XII MIPA SMAN 4 KOTA TANGERANG
}

\author{
Contemporary Application-Based E-Learning Multimedia Development On Geometry \\ Learning for Students of Class XII MIPA SMAN 4 Kota Tangerang
}

\author{
Dwi Mulyo
}

SMA Negeri 4 Kota Tangerang, Provinsi Banten, dwimulyo1972@gmail.com

\begin{abstract}
The industrial revolution 4.0 brings up an era of education that demands the use of Information and Communication Technology (ICT) in the learning process, to match the output with the need and demand of times. The existence of abstract concepts and difficulties in imagining the spatial aspect are obstacles for students of class XII MIPA SMAN 4 Kota Tangerang in learning to draw part of solid. Therefore, the development of learning media to help students learning it easily in an interesting, exciting, fun way and in accordance with the direction of education 4.0 is necessary. This research is a development research that aims to develop and determine the feasibility of multimedia e-learning which is based on Screencast O Matic and Powerpoint assisted by Geogebra and Kahoot in learning geometry for students of Class XII MIPA SMAN 4 Kota Tangerang. Nowadays, Screencast O Matic, Powerpoint, Geogebra and Kahoot are contemporary applications frequently used by teachers in making learning media. Among the Four-D development model which includes the define, design, develop, and disseminate stages, the developer does not do the dissemination stage because it is only a product feasibility test. At the develop stage, an expert assessment was carried out consisting of assessment for the content, media, language, and teacher / practitioner assessment and finally a development test. Based on the expert's assessment, the average score for the content aspect is 4.52 (Very Feasible), the media aspect is 4.22 (Very Appropriate), and the language aspect is 4.23 (Very Feasible). Based on the students' responses to the development test, it was obtained that the material aspects were 4.29 (very feasible), the media aspects were 4.11 (feasible), and the language aspects were 4.1 (feasible).
\end{abstract}

Keywords: Geometry Learning, E-Learning Multimedia , Contemporaryt Aplications,

Abstrak. Revolusi industri 4.0 melahirkan era pendidikan yang menuntut pemanfaatan Teknologi Informasi dan Komunikasi (TIK) pada proses pembelajaran, agar output sesuai kebutuhan dan tuntutan zaman. Adanya konsep abstrak dan kesulitan membayangkan aspek keruangan menjadi hambatan siswa kelas XII MIPA SMAN 4 Kota Tangerang dalam pembelajaran melukis irisan bangun ruang. Oleh karena itu dibutuhkan pengembangan media pembelajaran yang mampu membantu siswa mempelajarinya dengan mudah tapi terkemas menarik, seru, menyenangkan serta sesuai dengan arah pendidikan 4.0. Penelitian ini merupakan penelitian pengembangan yang bertujuan mengembangkan dan mengetahui kelayakan multimedia $e$-learning berbasis Screencast O Matic dan Powerpoint berbantuan Geogebra dan Kahoot pada pembelajaran geometri siswa kelas XII MIPA SMAN 4 Kota Tangerang. Screencast O Matic, Powerpoint, Geogebra dan Kahoot adalah aplikasi kekinian yang sering digunakan dalam pembuatan media pembelajaran oleh guru saat ini. Menggunakan model pengembangan Four-D yang meliputi tahap define, design, develop, dan disseminate, pengembang tidak melakukan tahap disseminate dikarenakan yang dilakukan hanya sekedar uji coba kelayakan produk. Pada tahap develop dilakukan penilaian para ahli yang terdiri dari penilaian aspek materi, media, bahasa, dan penilaian guru/praktisi serta terakhir dilakukan uji pengembangan. Berdasarkan penilaian ahli, skor rata-rata aspek materi adalah sebesar 4,52 (Sangat Layak), aspek media 4,22 (Sangat Layak), dan aspek bahasa 4,23 (Sangat Layak). Berdasarkan respon siswa pada uji pengembangan diproleh rata-rata aspek materi sebesar 4,29 (Sangat Layak), aspek media 4,11 (Layak), dan aspek bahasa 4,1 (Layak).

Kata kunci: Pembelajaran Geometri, Multimedia E-Learning, Aplikasi Kekinian 


\section{PENDAHULUAN}

Hadirnya era revolusi industri 4.0 telah melahirkan era pendidikan yang memunculkan harapan lahirnya generasi yang kreatif, inovatif, serta kompetitif. Pendidikan di era revolusi industri 4.0 menuntut optimalisasi penggunaan teknologi sebagai alat bantu pada proses pembelajaran, yang diharapkan mampu menghasilkan output yang dapat mengikuti atau mengubah zaman menjadi lebih baik. Pada lingkup pendidikan di Sekolah Menengah Atas (SMA/MA), pelajaran matematika terutama materi Bangun Ruang (Geometri) dikenal mempunyai karakteristik konsep yang abstrak sehingga berkembang anggapan-anggapan yang menyatakan bahwa pelajaran matematika khususnya geometri ruang merupakan pelajaran yang sulit dan menakutkan. Adanya konsep yang abstrak dan berkembangnya anggapan yang menyesatkan tersebut, menimbulkan siswa menjadi kurang tertarik terhadap pelajaran matematika, acuh sikapnya dan berkurang minatnya terhadap pelajaran itu.

Selama ini, mata pelajaran matematika disajikan secara konvensional melalui tatap muka di kelas, yang didominasi oleh metode ceramah. Metode pembelajaran seperti ini masih berpusat pada guru, belum melibatkan teknologi sesuai tuntutan pendidikan era revolusi industri 4.0, sehingga tidak mampu meningkatkan peran aktif siswa dalam proses pembelajaran, dan kurang memberikan peluang kepada siswa untuk mengekspresikan pemahaman dan keterampilannya. Siswa millenial seperti saat ini memang menuntut pembelajaran yang dikolaborasikan dengan teknologi dan mampu dikemas lebih menarik, seru dan menyenangkan.

Dalam makalah yang disampaikan pada seminar "Pemanfaatan Teknologi Informasi dan Komunikasi Untuk Pendidikan Jarak Jauh dalam Rangka Peningkatan Mutu Pembelajaran” yang diselenggarakan oleh Pustekkom Depdiknas tanggal 12 Desember 2006 di Jakarta, Guru Besar UPI Bandung, Mohamad Surya, menyatakan bahwa hal yang paling mutakhir pada masa sekarang ini adalah berkembangnya apa yang disebut "cyber teaching" atau pengajaran Maya, yaitu proses pembelajaran yang dilakukan dengan menggunakan internet. Istilah lain yang makin populer saat ini ialah $e$ learning yaitu satu model pembelajaran dengan menggunakan media Teknologi Komunikasi dan Informasi khususnya Internet. Menurut Darin E. Hartley (2001), e-learning merupakan suatu jenis belajar mengajar yang memungkinkan tersampaikannya bahan ajar ke siswa dengan menggunakan media internet, intranet atau media jaringan komputer lainnya. Sedangkan Thomas Toth (2003) menyatakan bahwa E-learning adalah semua yang mencakup pemanfaatan komputer dalam menunjang peningkatan kualitas pembelajaran, termasuk di dalamnya penggunaan mobile technologies seperti PDA dan MP3 players serta penggunaan teaching materials berbasis web dan hypermedia, multimedia CD-ROM atau web sites, forum diskusi, perangkat lunak kolaboratif, email, blogs, computer aided assessment, animasi pendidikan, simulasi, permainan, perangkat lunak manajemen pembelajaran, electronic voting systems, dan lain-lain. Dengan menggunakan cyber teaching atau e-learning ini maka guru dapat memberikan layanan tanpa harus berhadapan langsung dengan siswa. Demikian pula siswa dapat memperoleh informasi dalam lingkup yang luas dari berbagai sumber melalui cyber space atau ruang maya dengan menggunakan komputer atau internet (Surya, 2006).

Dengan demikian, penggunaan e-learning dalam pembelajaran di kelas merupakan kebutuhan yang mendesak dan tidak bisa ditunda-tunda lagi pemanfaatannya. Hal ini mudah dipahami, mengingat proses belajar yang dialami siswa bergantung pada berbagai kegiatan menambah ilmu dan wawasan untuk bekal hidup di masa sekarang dan masa akan datang, sehingga harus dilakukan dengan menciptakan situasi belajar yang memungkinkan terjadinya proses pengalaman belajar pada diri siswa dengan menggerakan segala sumber belajar, teknologi dan cara belajar yang efektif dan efisien. Dalam hal ini, media pembelajaran berciri cyber teaching merupakan salah satu solusi yang efektif 
dalam membantu terjadinya proses belajar. Metode pembelajaran dengan ciri tersebut, yang dirasa menarik dan efektif bagi siswa kelas XII MIPA SMAN 4 Kota Tangerang adalah dengan menggabungkan berbagai media baik berupa aplikasi maupun software komputer menjadi satu multimedia berbasis TIK dan internet. Media pembelajaran semacam ini sering disebut sebagai multimedia $e$-learning, dapat berupa penggabungan video pembelajaran yang dibuat dengan aplikasi Screencast $O$ Matic (atau yang lainnya) yang ditampilkan sebagai sebuah display pembelajaran PowerPoint, berbantuan program-program pembelajaran matematika populer semisal Geogebra dan Wingeom yang dapat dikolaborasikan dengan platform pembelajaran berbasis games yang menarik semacam Kahoot, Quizizz, Quizlet, dan lain-lain.

Screencast $O$ Matic adalah sebuah aplikasi berbasis Java yang digunakan untuk membuat screencasts pada sistem operasi Windows, Mac, dan Linux. Screencast O Matic memberikan layanan software gratis yang memungkinkan pengguna untuk merekam semua tampilan dan gerakan dari layar monitor, baik itu gerakan kursor maupun klik indikator, mudah untuk digunakan, dan dapat menambahkan keterangan atau komentar dengan mudah (Rini Fadhillah Putri dan Rizqy Fadhlina Putri, 2018). Geogebra adalah program komputer (software) untuk membelajarkan matematika khususnya geometri dan aljabar (Hohenwarter, 2008). Program ini dapat dimanfaatkan secara bebas yang dapat diunduh dari www.Geogebra.com. Microsoft Powerpoint adalah sebuah program aplikasi microsoft office yang berguna sebagai media presentasi dengan menggunakan beberapa slide. Aplikasi ini sangat digemari dan banyak digunakan dari berbagai kalangan, baik itu pelajar, perkantoran dan bisnis, pendidik, dan trainer. Kahoot adalah permainan berbasis platform pembelajaran gratis (https://id.wikipedia.org/wiki/Kahoot!), sebagai teknologi pendidikan yang kental sekali nuansa pendidikan 4.0. Diluncurkan pada Agustus 2013 dari Norwegia, Kahoot sekarang dimainkan oleh lebih dari 50 juta orang di 180 negara.

\section{METODE PENELITIAN}

Jenis penelitian ini merupakan penelitian pengembangan (Research and Development) (Sugiyono, 2010) dan dilaksanakan di kelas XII MIPA 6 SMA Negeri 4 Kota Tangerang, Provinsi Banten pada semester ganjil tahun ajaran 2019-2020. Waktu penelitian berlangsung selama kurang lebih 6 bulan yakni dari bulan April sampai dengan September 2019. Penelitian ini dirancang dengan menggunakan model Four-D yang dikembangkan oleh Thiagarajan dan Semmel (1974) dimana terdapat 4 tahapan yaitu tahap pendefinisian (Define), perancangan (Design), pengembangan (Develop), dan penyebaran (Disseminate), tetapi pada model pengembangan ini hanya digunakan 3 tahapan yang pertama saja sedangkan tahap penyebaran (Disseminate) tidak dilakukan. Hal ini diputuskan dengan pertimbangan bahwa pengembangan media ajar hanya sebatas uji coba prototipe produk. Tahapan keempat (Disseminate/penyebaran) tidak dilakukan karena berada di luar sistem pembelajaran, sehingga dalam pengembangan ini tidak digunakan. Alur Pengembangan Media Pembelajaran dapat dilihat di gambar 1 . 


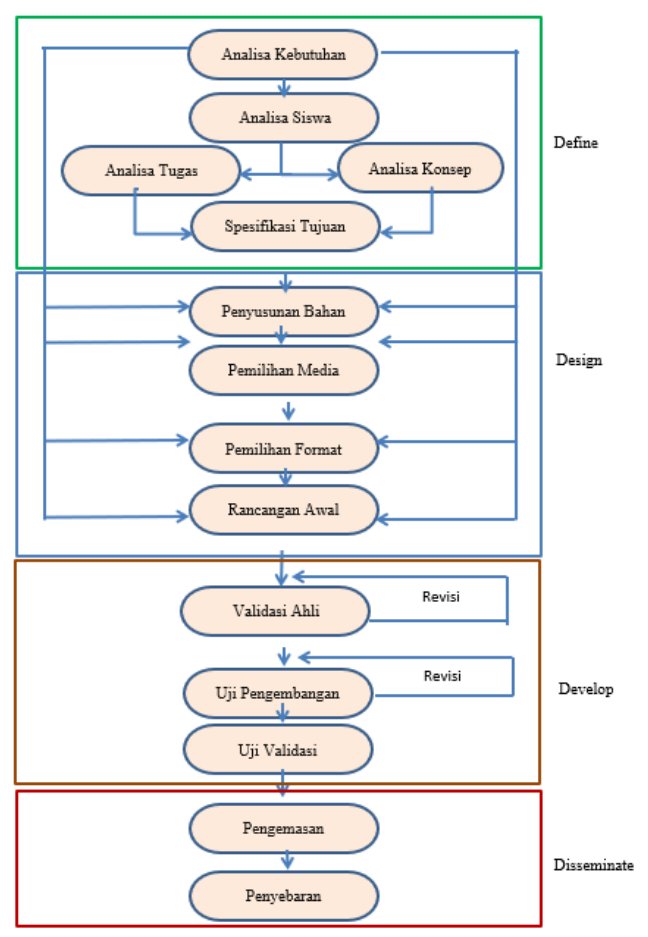

Gambar 1. Alur Pengembangan Media Pembelajaran

\section{Spesifikasi Produk yang Dikembangkan}

1. Produk merupakan media pembelajaran berbentuk slide pembelajaran powerpoint yang berisi materi pokok Melukis Irisan Bangun Ruang kelas XII MIPA semester ganjil.

2. Media pembelajaran (produk) tersebut memuat:

a. Video pembelajaran yang dibuat dengan aplikasi Screencast O Matic dimana konten yang divideokan dibuat dengan fasilitas animasi powerpoint.

b. Tampilan dinamis dari proses melukis bangun ruang yang dibuat dengan aplikasi Geogebra yang bisa diubah-ubah secara real time,

c. Kuis/games perangsang di awal pembelajaran (tahap apersepsi) dengan aplikasi Kahoot,

d. Animasi yang memuat: teks, audio, gambar diam (image), animasi (gambar bergerak).

3. Konten yang divideokan dibuat sendiri dengan fasilitas powerpoint dan disisipkan suara peneliti (dubbing) serta berbentuk animasi visual tahap demi tahap proses melukis irisan bangun ruang.

4. Slide pembelajaran memuat pendahuluan, isi, penutup, serta dilengkapi dengan alamat url file LKS, file kuis Kahoot, file contoh soal, latihan dan tugas mandiri serta file-file Geogebra yang dibutuhkan.

5. Guru dan siswa dapat dengan mudah menggunakan slide pembelajaran ini karena telah dilengkapi cara penggunaanya dan bisa diunduh di alamat $u r l$ yang sudah disediakan peneliti.

Gambar-gambar berikut ini memberikan gambaran tentang produk yang peneliti kembangkan. 


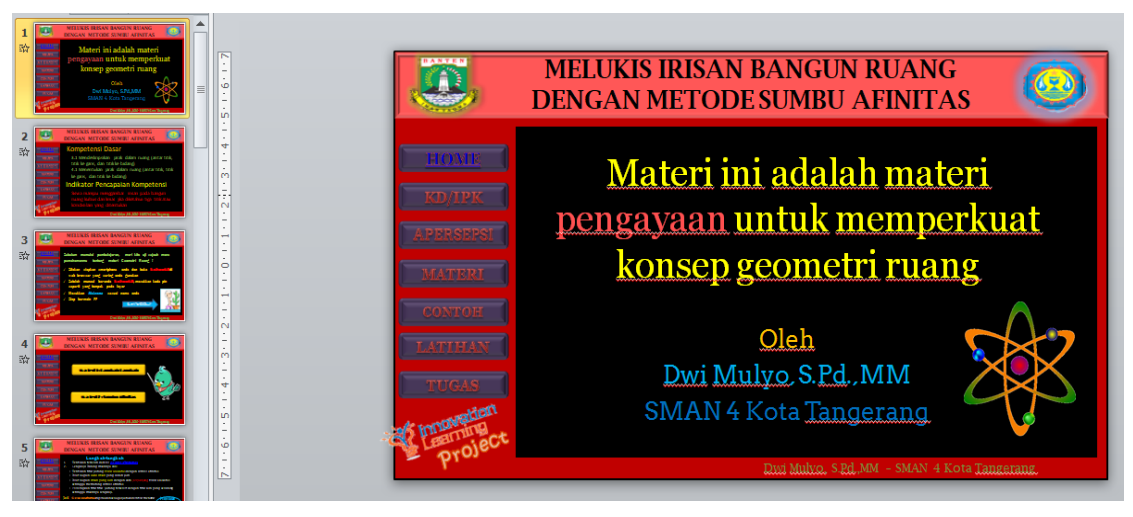

Gambar 2. Slide Home Media Pembelajaran

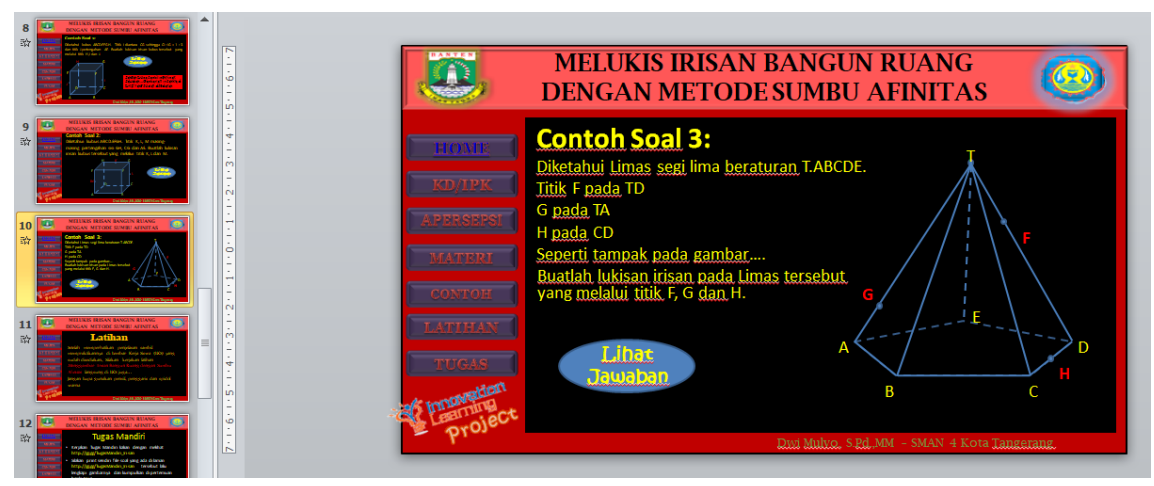

Gambar 3. Slide Contoh Soal 3

\section{Jalannya Penelitian}

1. Produk diputar di depan kelas selama 2 jam pelajaran $(2 \times 45$ menit)

2. Saat apersepsi, siswa diputarkan game Kahoot it. Semua siswa bermain dengan menggunakan HP masing-masing. Keseruan, kegembiraan dan antusiasme siswa sangat terasa saat game ini dimainkan.

3. Penjelasan awal tentang materi dan penyelesaian contoh soal oleh guru menggunakan penjelasan konvensional berbantuan Geogebra.

4. Untuk makin memperjelas materi dan contoh soal, siswa kemudian diputarkan 3 video pembelajaran berisi langkah-langkah melukis irisan yang ditampilkan secara tahap demi tahap.

5. Sambil memperhatikan video yang diputar, siswa mengisi/melukis gambar bangun ruang di LKS yang telah disediakan.

6. Gambar bangun ruang di LKS yang harus dilengkapi irisannya oleh siswa, sudah di-setting sesuai dengan contoh di video pembelajaran, berjumlah 3 gambar/soal. Setelah selesai, siswa kemudian mengerjakan latihan dengan mengerjakan 3 gambar sisanya di LKS juga. Jadi soal melukis irisan bangun ruang di LKS semuanya ada 6 buah.

7. Semua LKS siswa yang berisi penyelesaian 6 lukisan irisan bangun ruang, dikumpulkan sebagai hasil belajar hari itu, yang akan diperiksa dan dinilai oleh guru.

8. Di akhir pelajaran, guru mengarahkan siswa untuk mencatat link tugas melukis irisan bangun ruang sebagai $\mathbf{P R}$ yang harus dikerjakan dan dikumpulkan minggu berikutnya. 


\section{HASIL DAN PEMBAHASAN}

Tahapan dalam penelitian pengembangan ini adalah sebagai berikut:

\section{Tahap Define (Pendefinisian)}

Tahap Define bertujuan untuk menetapkan dan mendefinisikan syarat-syarat pembelajaran. Tahap ini meliputi lima langkah pokok, berikut penjelasannya:

a. Analisis kebutuhan

Analisis kebutuhan bertujuan untuk memunculkan dan menetapkan masalah dasar yang dihadapi dalam pembelajaran geometri ruang terutama bahasan melukis irisan bangun ruang di SMA sehingga dibutuhkan pengembangan media pembelajaran. Pada tahap ini, dilakukan observasi dan diskusi dengan Guru Mata Pelajaran Matematika SMA Negeri 4 Kota Tangerang untuk mengetahui kegiatan pembelajaran di sekolah, termasuk di dalamnya kurikulum yang digunakan, metode pembelajaran dan media pembelajaran yang digunakan guru. Tahap ini bertujuan untuk mendapatkan informasi tentang kondisi, fakta dan permasalahan tentang pembelajaran matematika khususnya bahasan geometri ruang di lapangan sehingga dibutuhkan pengembangan media pembelajaran.

b. Analisis Siswa

Analisis siswa dilakukan pada awal perencanaan, analisis ini dilakukan dengan mempertimbangkan ciri, kemampuan dan pengalaman siswa, baik sebagai kelompok maupun individu. Analisis siswa meliputi kemampuan akademik, usia, tingkat kedewasaaan, motivasi belajar terhadap mata pelajaran matematika. Pada usia ini anak berpikir pada tahap operasional formal, dalam arti anak sudah berpikir logis dalam berbagai situasi, anak sudah dapat menggunakan pola pikir yang sistematis dengan otaknya dan meliputi proses yang kompleks.

c. Analisis tugas

Analisis tugas adalah kemampuan prosedur untuk menentukan isi dalam satuan pembelajaran. Analisis tugas dilakukan untuk merinci isi materi ajar dalam bentuk garis besar. Analisis ini mencakup: (1) analisis struktur isi, (2) analisis prosedural, (3) analisis proses informasi, (4) analisis konsep, dan (5) perumusan tujuan.

d. Analisis konsep

Analisis konsep dilakukan untuk memilih, merinci, dan menetapkan secara sistematis konsep yang relevan yang akan diajarkan berdasarkan analisis kebutuhan. Analisis ini menjadi dasar dalam penyusunan tujuan pembelajaran.

e. Spesifikasi tujuan pembelajaran

Tahap ini dilakukan untuk merumuskan hasil analisis konsep dan analisis tugas yang sebelumnya telah dilakukan. Indikator tersebut selanjutnya akan menjadi tujuan pembelajaran yang akan dicapai oleh siswa dan sekaligus sebagai dasar penyusunan butir contoh soal dan soal latihan.

\section{Tahap Design (Perancangan)}

Tujuan tahap ini adalah menyiapkan disain awal media pembelajaran atau disain produk. Tahap ini terdiri dari 4 langkah yaitu:

1. Penyusunan Bahan-Bahan Pendukung Media 
Penyusunan bahan-bahan untuk konten media antara lain membuat video pembelajaran dengan powerpoint dan screencast o matic, konten geogebra dan soal kuis di aplikasi kahoot.it.

2. Pemilihan Media

Pemilihan media disesuaikan dengan tujuannya untuk menyampaikan materi pelajaran dan faktor kemudahan di dalam penyediaan peralatan yang diperlukan sehingga memudahkan tercapainya tujuan pembelajaran. Konten-konten yang sudah dibuat secara terpisah kemudian disatukan dalam media yang dipilih untuk dipakai pada pembelajaran. Dalam pembelajaran geometri topik melukis irisan bangun ruang, akan digunakan media pembelajaran berupa multimedia e-learning berbasis Screencast $O$ Matic dan Powerpoint berbantuan Geogebra dan Kahoot pada pembelajaran geometri siswa kelas XII MIPA.

3. Pemilihan format

Pemilihan format dilakukan dengan memilih format media pembelajaran geometri ruang yang akan dibuat. Pemilihan format ini disesuikan dengan subyek penelitian, yaitu siswa SMA.

4. Rancangan awal (disain awal)

Rancangan awal atau disain awal ini merupakan hasil awal rancangan produk yang akan dikembangkan.

Sebelum diujikan pada subjek penelitian, disain awal media yang dikembangkan harus divalidasi terlebih dahulu oleh ahli dan praktisi. Tujuannya adalah untuk mengetahui kelayakan disain awal media tersebut. Nama-nama validator tersebut dapat dilihat pada tabel 1 di bawah ini.

Tabel 1. Nama-nama Validator Ahli dan Praktisi

\begin{tabular}{cccc}
\hline No & Nama & Mata Pelajaran & Peran \\
\hline 1. & Dra. Hj. Ismelda, M.Pd & Matematika & Guru Ahli Materi \\
\hline 2. & Sari Hidayati, S.Kom & TIK & Guru Ali Media \\
\hline 3. & Suherman, M.Pd & Bahasa Indonesia & Guru Ahli Bahasa \\
\hline 4. & Wahib Robbi Nugroho, S.Pd & Matematika & Guru Praktisi \\
\hline
\end{tabular}

\section{Hasil penilaian aspek materi}

Materi dalam media yang dikembangkan ini dinilai dan ditinjau oleh ahli materi dan praktisi (guru). Hasil penilaian berupa data kuantitatif yang didapat dari skor setiap butir aspek dan data kualiatif yang diperoleh dari uraian perbaikan serta saran yang diberikan. Data kuantitatif tersebut kemudian dikonversikan menjadi data kualitatif untuk mengetahui kelayakan dari aspek materi. Sedangkan data kualitatif digunakan untuk revisi media pembelajaran. Hasil rata-rata penilaian aspek materi disajikan pada tabel 2 .

Tabel 2. Hasil Penilaian Aspek Materi

\begin{tabular}{llcc}
\hline No & Kriteria & \multicolumn{2}{c}{ Skor } \\
& & $\begin{array}{c}\text { Validasi Ahli } \\
\text { Materi }\end{array}$ & $\begin{array}{c}\text { Validasi } \\
\text { Praktisi (Guru) }\end{array}$ \\
\hline 1. & Kesesuaian materi tujuan & 5 & 5 \\
\hline 2. & Kedalaman materi & 5 & 4 \\
\hline 3. & Sistematis, runtut, alur logika jelas & 5 & 4 \\
\hline 4. & Kejelasan rumusan soal & 5 & 4 \\
\hline 5. & Kelengkapan soal & 5 & 4 \\
\hline 6. & Kebenaran konsep soal & 5 & 4 \\
\hline
\end{tabular}




\begin{tabular}{llcc}
\hline No & \multicolumn{1}{c}{ Kriteria } & \multicolumn{2}{c}{ Skor } \\
& & $\begin{array}{c}\text { Validasi Ahli } \\
\text { Materi }\end{array}$ & $\begin{array}{c}\text { Validasi } \\
\text { Praktisi (Guru) }\end{array}$ \\
\hline 7. & Konsistensi evaluasi dengan tujuan pembelajaran & 4 & 5 \\
\hline 8. & Kekomunikatifan Bahasa & 5 & 4 \\
\hline 9. & Ketepatan Penggunaan istilah, simbol atau ikon & 5 & 3 \\
\hline 10. & Pemberian motivasi belajar & 5 & 4,5 \\
\hline \multicolumn{2}{c}{ Rata-rata Skor } & $\mathbf{4 , 9 0}$ & $\mathbf{4 , 1 5}$ \\
\hline
\end{tabular}

Sumber: Hasil pengolahan dari data primer penelitian

Untuk memperoleh gambaran tentang layak atau tidaknya media yang dikembangkan, rerata skor tiap aspek yang diperoleh kemudian dibandingkan dengan pedoman konversi data kuantitatif ke data kualitatif skala 5 seperti tabel 3 di bawah ini.

Tabel 3. Pedoman Konversi Data Kuantitatif ke Data Kualitatif Skala 5

\begin{tabular}{cccc} 
Skor & Interval & Nilai & Kategori \\
\hline $\mathbf{5}$ & $\bar{X}>4,2$ & A & Sangat Layak \\
\hline $\mathbf{4}$ & $3,4<\bar{X} \leq 4,2$ & B & Layak \\
$\mathbf{3}$ & $2,6<\bar{X} \leq 3,4$ & C & Cukup Layak \\
\hline $\mathbf{2}$ & $1,8<\bar{X} \leq 3,4$ & D & Kurang Layak \\
\hline $\mathbf{1}$ & $\bar{X} \leq 1,8$ & E & Sangat Kurang Layak
\end{tabular}

Keterangan:

$\bar{X}: \quad$ Skor aktual

$\mathrm{X}_{\mathrm{t}}$ : $\quad$ Rerata skor ideal $\quad=1 / 2($ skor maksimal ideal + skor minimal ideal $)$

$$
\begin{aligned}
& =1 / 2(5+1) \\
& =3
\end{aligned}
$$

(Eko P. Widoyoko, 2013)

Pada tabel 2, rata-rata skor aspek materi dalam multimedia yang dikembangkan adalah sebesar 4,52. Hal ini menunjukan bahwa dari aspek materi, media ini masuk kategori "Sangat Layak".

\section{Hasil penilaian aspek media}

Aspek media dinilai oleh seorang ahli media dan seorang praktisi. Hasil penilaian ditunjukkan pada tabel 4.

Tabel 4. Hasil Penilaian Aspek Media

\begin{tabular}{clcc}
\hline No & \multicolumn{1}{c}{ Kriteria } & \multicolumn{2}{c}{ Skor } \\
\cline { 3 - 4 } & & $\begin{array}{c}\text { Validasi Ahli } \\
\text { Media }\end{array}$ & $\begin{array}{c}\text { Validasi Praktisi } \\
\text { (Guru) }\end{array}$ \\
\hline 1. & Efektif dan efisien penggunaan sumber daya & 4,5 & 4 \\
\hline 2. & Reliabilitas media & 4 & 4 \\
\hline 3. & Kompatibilitas media & 4 & 3,5 \\
\hline 4. & Penggunaan media & 4 & 5 \\
\hline 5. & Komunikatif & 5 & 4 \\
\hline 6. & Kreatif & 4,67 & 4,67 \\
\hline 7. & Visual & 4 & 4,5 \\
\hline 8. & Animasi & 3 & 5 \\
\hline 9. & Ikon Navigasi & 4 & $\mathbf{4 , 3 0}$ \\
\hline \multicolumn{7}{r}{} & Rata-rata Skor & $\mathbf{4 , 1 3}$ & $\mathbf{4 , 2 2}$ \\
\hline Rata-rata Skor Validasi Ahli Media
\end{tabular}

Sumber: Hasil pengolahan dari data primer penelitian 
Pada tabel 4 mengenai hasil penilaian aspek media, rata-rata skor aspek media dalam multimedia $e$ learning yang dikembangkan adalah sebesar 4,22 (Sangat Layak).

\section{Hasil penilaian aspek bahasa}

Aspek bahasa dalam multimedia e-learning yang dikembangkan ini dinilai oleh seorang ahli bahasa dan seorang guru/praktisi. Hasil penilaiannya bisa dilihat pada tabel 5 di bawah ini.

Tabel 5. Hasil Penilaian Aspek Bahasa

\begin{tabular}{llcc}
\hline No & Kriteria & \multicolumn{2}{c}{ Skor } \\
\cline { 3 - 4 } & & $\begin{array}{c}\text { Validasi Ahli } \\
\text { Bahasa }\end{array}$ & $\begin{array}{c}\text { Validasi Praktisi } \\
\text { (Guru) }\end{array}$ \\
\hline 1. & Kesederhanaan Bahasa & 4 & 4,5 \\
\hline 2. & Kesesuaian bahasa dengan tingkat kognitif siswa & 4 & 4,5 \\
\hline 3. & Penggunaan bahasa yang komunikatif & 5 & 5 \\
\hline 4. & Ketepatan penggunaan istilah & 4 & 4 \\
\hline $5 . \quad$ Kesesuaian Bahasa dengan EYD & 4 & 4 \\
\hline Rata-rata Skor & $\mathbf{4 , 2}$ & $\mathbf{4 , 4}$ \\
\hline Rata-rata Skor Validasi Ahli Bahasa & & $\mathbf{4 , 3 0}$ \\
\hline
\end{tabular}

Sumber: Hasil pengolahan dari data primer penelitian

Pada tabel 5 mengenai hasil penilaian aspek bahasa, rata-rata skor aspek bahasa dalam multimedia e-learning yang dikembangkan adalah sebesar 4,30 (Sangat Layak).

\section{Uji Pengembangan}

Sebelum media diujikan pada siswa, terlebih dahulu dilakukan uji pengembangan pada 10 siswa SMAN 4 Kota Tangerang kelas XII MIPA 6. Tujuan dari dilakukannya uji pengembangan ini adalah untuk mengetahui respon siswa terhadap media pembelajaran yang dikembangkan. Hasil dari uji pengembangan ini ditunjukkan pada tabel 6 .

Tabel 6. Hasil Uji Pengembangan

\begin{tabular}{llll}
\hline No & Aspek & Nilai Rata-Rata & Kriteria \\
\hline 1. & Materi & 4,29 & Sangat layak \\
\hline 2. & Media & 4,11 & layak \\
\hline 3. & Bahasa & 4,1 & layak \\
\hline
\end{tabular}

Sumber: Hasil pengolahan dari data primer penelitian

Berdasarkan hasil uji pengembangan, menunjukkan bahwa nilai rata-rata aspek materi sebesar 4,29 (Sangat layak), aspek media sebesar 4,11 (layak), dan aspek bahasa sebesar 4,1 (layak). Dari 10 siswa yang memberi penilaian, 8 orang menyimpulkan media layak diujicobakan di lapangan dengan revisi dan 2 orang siswa menyatakan media layak diujicobakan di lapangan tanpa ada revisi. Berdasarkan penilaian tersebut, dapat diartikan bahwa multimedia e-learning yang dikembangkan ini dapat digunakan untuk pembelajaran siswa.

Berdasarkan pengamatan pada proses penelitian pengembangan media pembelajaran ini, dapat dijabarkan hal-hal sebagai berikut:

1. Semua siswa mampu memahami pembelajaran materi melukis irisan bangun ruang yang disajikan dengan multimedia e-learning berbasis aplikasi kekinian dengan baik dan bersemangat. 
2. Pada aspek media, siswa memiliki respon positif yaitu siswa meminta untuk dibuatkan media serupa tapi untuk materi yang berbeda dan mereka mengaku sangat terkesan serta antusias ketika diadakan permainan kuis Kahoot.

3. Pada aspek materi, siswa mengaku mampu memahami pembelajaran dengan baik dengan adanya penjelasan materi berbantuan Geogebra dan merasa sangat terbantu dengan adanya penayangan video pembelajaran yang disertai lembar kerja siswa (LKS).

4. Pada aspek bahasa, siswa mampu memahami bahasa yang digunakan dalam media yang dikembangkan ini dengan baik.

5. Ada beberapa hal yang perlu diperbaiki dalam media ini namun secara keseluruhan media ini sudah dianggap layak dan mampu membantu pembelajaran serta menarik dalam pemanfaatannya.

Gambar-gambar berikut ini menampilkan contoh revisi dari ahli media dan ahli bahasa, sebagai berikut:

1. Ahli media menyoroti masalah tombol navigasi dan animasi video yang kurang layak dan harus diperbaiki.

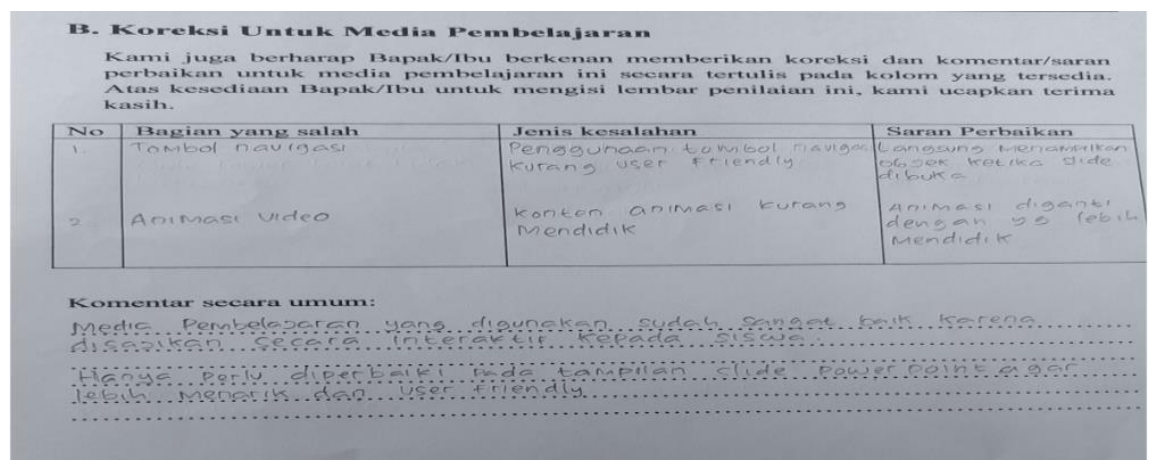

Gambar 4. Screenshoot Penilaian/revisi oleh Ahli Media

2. Ahli bahasa sebagian besar menyoroti penggunaan beberapa istilah dan ejaan yang kurang tepat misalnya Pada slide 3, kata 'sejauh mana' dianggap menyalahi diksi atau kurang tepat dalam pilihan kata sehingga direvisi menjadi 'seberapa jauh'.
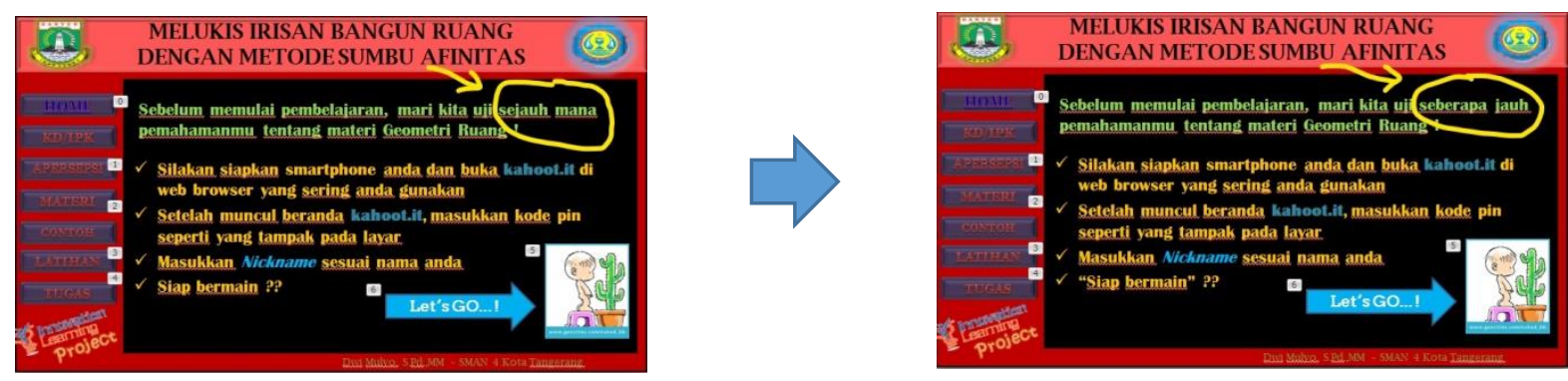

Gambar 5. Screenshoot Penilaian/revisi oleh Ahli Bahasa

\section{Keterbatasan Penelitian Pengembangan}

Berdasarkan penelitian yang telah dilakukan, keterbatasan penelitian pengembangan media ini adalah sebagai berikut:

a. Media yang dihasilkan masih termasuk pada pengembangan tingkat pemula yang hanya mencakup satu materi matematika yaitu materi geometri melukis irisan bangun ruang. 
b. Validasi media baru sebatas dilakukan oleh 1 ahli materi, 1 ahli media, 1 ahli bahasa, dan 1 praktisi pembelajaran matematika.

c. Media yang dikembangkan masih terbatas pada pemanfaatan fungsi-fungsi pada aplikasi-aplikasi yang sederhana seperti PowerPoint, Geogebra, Screencast o matic dan aplikasi games Kahoot.

\section{KESIMPULAN DAN REKOMENDASI}

\section{Kesimpulan}

1. Pengembangan multimedia e-learning berbasis aplikasi kekinian pada pembelajaran geometri siswa kelas XII MIPA SMA Negeri 4 Kota Tangerang dikembangkan dengan model Four-D yang dilakukan melalui 3 dari 4 tahap yaitu tahap define, design, develop, dan disseminate.

2. Hasil pengembangan multimedia e-learning yang dilakukan oleh ahli materi, ahli media dan ahli bahasa ini menunjukkan bahwa skor rata-rata aspek materi adalah sebesar 4,52 (Sangat Layak), aspek media sebesar 4,22 (Sangat Layak) dan aspek bahasa sebesar 4,30 (Sangat Layak). Berdasarkan penilaian ini, dinyatakan bahwa media pembelajaran ini sangat layak digunakan sebagai media pembelajaran pada materi melukis irisan bangun ruang untuk siswa kelas XII SMA.

\section{Rekomendasi}

1. Multimedia e-learning berbasis aplikasi kekinian pada pembelajaran geometri siswa kelas XII MIPA SMA Negeri 4 Kota Tangerang ini dapat digunakan sebagai sarana penunjang pembelajaran matematika materi melukis irisan bangun ruang untuk siswa kelas XII SMA.

2. Multimedia e-learning berbasis aplikasi kekinian pada pembelajaran geometri siswa kelas XII MIPA SMA Negeri 4 Kota Tangerang ini perlu dikembangkan lebih lanjut mengenai tampilan, sehingga dapat lebih jelas dan lebih menarik lagi dan hendaknya dikembangkan lebih lanjut untuk materi-materi yang lainnya.

\section{DAFTAR PUSTAKA}

Darin E.Hartley, (2001). Selling E-learning, American Society for Training and Development. Eko P. Widoyoko. (2013).Teknik Penyusunan Instrumen Penelitian. Yogyakarta: Pustaka Pelajar Hohenwarter, M., et al. (2008). Teaching and Learning Calculus with Free Dynamic Mathematics Software Geogebra. Melalui<http://www. publications.uni.lu/ record /2718/files/ICME11TSG16.pdf.> [21 Mei 2020]

https://id.wikipedia.org/wiki/Kahoot! [23 Mei 2020]

Rini Fadhillah Putri dan Rizqy Fadhlina Putri. 2018. Keterampilan Berbicara Mahasiswa Dengan Integrasi Media Screencast O Matic Dengan Pembelajaran Inkuiri. Jurnal WAHANA INOVASI VOLUME 7 No.2 JULI-DES 2018. Melalui <https://penelitian.uisu.ac.id/wpcontent/uploads/2018/10/3.-Rini-Fadhillah-Putri.pdf> [23 Mei 2020]

Sugiyono. (2010). Metode Penelitian Kuantitatif, Kualitatif dan $R \& D$. Bandung: Penerbit Alfabeta

Surya, Mohamad (2006). Pemanfaatan Teknologi Informasi dan Komunikasi Untuk Pendidikan Jarak Jauh dalam Rangka Peningkatan Mutu Pembelajaran. Makalah Seminar yang diselenggarakan Pustekkom Depdiknas 12 desember 2006 di Jakarta. Melalui <https://www.slideshare.net/fajarbaskoro/potensi-teknologi-informasi-dan-komunikasidalam-peningkatan-mutu-pembelajaran-di-kelas?from_action=save [23 Mei 2020]

Thiagarajan, S., Semmel, D. S \& Semmel, M. I. (1974). Instructional Development for Training Teachers of Expectional Children. Minneapolis, Minnesota: Leadership Training Institute/Special Education, University of Minnesota.

Thomas Toth. (2003). E-learning. Melalui<.https://widuri.raharja.info> [23 Mei 2020] 